\title{
Platelet-derived growth factor modulates the primordial to primary follicle transition
}

\author{
Eric E Nilsson, Chris Detzel and Michael K Skinner \\ Center for Reproductive Biology, School of Molecular Biosciences, Washington State University, Pullman, \\ WA 99164-4231, USA \\ Correspondence should be addressed to M K Skinner; Email: skinner@wsu.edu
}

\begin{abstract}
Primordial follicles steadily leave the arrested pool and undergo a primordial to primary follicle transition during the female reproductive lifespan. When the available pool of primordial follicles is depleted reproduction ceases and humans enter menopause. The present study was designed to investigate the actions of several growth factors previously identified as candidate regulatory factors for the primordial to primary follicle transition with a microarray analysis. Ovaries from 4-day-old rats were placed into culture and treated for 2 weeks with platelet-derived growth factor (PDGF), anti-PDGF neutralizing antibody, vascular endothelial growth factor (VEGF), neuregulin (NRG), or kit ligand (KITL) as a positive control. PDGF-treatment resulted in a significant decrease in the percentage of primordial follicles and a concomitant increase in the percentage of developing primary follicles compared to controls. In contrast, ovaries treated with an anti-PDGF neutralizing antibody had a significant increase in the percentage of primordial follicles demonstrating an inhibition of endogenous follicle development. Ovaries incubated in the presence of VEGF or NRG had no change in follicle development. Observations indicate that PDGF, but not VEGF or NRG, promotes the primordial to primary follicle transition. Immunohistochemical localization indicated that the PDGF protein was present in the oocytes of both primordial and developing follicles. PDGF-treatment of cultured ovaries resulted in an increase in KITL mRNA expression. KITL has been previously shown to promote the primordial to primary follicle transition. KITLtreatment of ovaries had no effect on expression of Pdgf or any PDGF homologs or receptors. Therefore, PDGF appears to be produced by the oocyte and acts as one of several extracellular signaling factors that regulate the primordial to primary follicle transition. These observations provide insight into the cell-cell interactions involved in the regulation of primordial follicle development and can be used in the future development of therapies for some forms of infertility.

Reproduction (2006) 131 1007-1015
\end{abstract}

\section{Introduction}

In mammals most of the oocytes in an ovary are arrested in the first meiotic division and contained in primordial follicles. A primordial follicle is composed of an oocyte arrested in the diplotene stage of prophase I of meiosis and surrounded by a single layer of squamous pregranulosa cells. The pool of available primordial follicles is formed in the neonatal period and has been considered to be finite in number (Hirshfield 1991, Kezele et al. 2002a). Recent evidence raises the possibility that new follicles with oocytes may form in adulthood (Johnson et al. 2004, 2005). Over the course of a female reproductive lifespan, primordial follicles steadily leave the arrested pool and undergo a primordial to primary follicle transition in which the surrounding pre-granulosa cells become cuboidal and begin to proliferate (Peters et al. 1975, Cran \& Moor 1980,
Hirshfield 1991, Rajah et al. 1992). These developing follicles gain successive layers of granulosa cells and theca cells, while the oocyte increases in size. Eventually, a fluid-filled antrum is formed. While many developing follicles undergo atresia and apoptosis, some continue to develop until they ovulate. When the available pool of primordial follicles is depleted, reproduction ceases and humans enter menopause (Gosden et al. 1983, Richardson et al. 1987, Faddy et al. 1992, Faddy 2000).

Several paracrine growth factors have been shown to act locally within the ovary to regulate the primordial to primary follicle transition. Bone morphogenetic protein 15 (BMP15), basic fibroblast growth factor (bFGF/FGF2), the neurotrophins NT4 and bone-derived neurotropic factor (BDNF), the c-kit receptor for kit ligand (KITL) and the Trk-B receptor for NT4 and BDNF are all present in the oocytes of primordial follicles. All these growth factors 
and receptors have been implicated in promoting the primordial to primary follicle transition (Manova et al. 1990, Horie et al. 1991, van Wezel et al. 1995, Dube et al. 1998, Laitinen et al. 1998, Parrott \& Skinner 1999, Nilsson et al. 2001, Paredes et al. 2004). Several growth factors found to be present in the pre-granulosa cells surrounding primordial follicles or in granulosa cells were also found to promote the primordial to primary follicle transition including KITL and leukemia inhibitory factor (LIF) (Manova et al. 1993, Motro \& Bernstein 1993, van Wezel et al. 1995, Yamamoto et al. 1997, Parrott \& Skinner 1999, Nilsson et al. 2001). The thecal/interstitial cells surrounding follicles express bone morphogenetic protein 4 (BMP4) and BMP7, both of which promote the primordial to primary follicle transition. BMP4 has also been shown to be important for follicle survival (Lee et al. 2001, Nilsson \& Skinner 2003). Anti-Müllerian hormone/ Müllerian inhibitory substance (AMH/MIS) is a growth factor produced by the granulosa cells of developing preantral and antral follicles which inhibits the primordial to primary follicle transition (Baarends et al. 1995, Durlinger et al. 1999, 2002).

Platelet-derived growth factor (PDGF), neuregulin (NRG) and vascular endothelial growth factor (VEGF) were all identified as candidate signaling factors to regulate the primordial to primary follicle transition with a microarray analysis previously performed (Kezele et al. 2005b). These factors change mRNA expression levels during primordial to primary follicle transition, suggesting that they may regulate early follicle development (Kezele et al.2005b). The present study was designed to investigate the potential regulatory roles of PDGF, VEGF and NRG in primordial to primary follicle transition.

The most prevalent isoforms of PDGF are the PDGF$A A$, PDGF-BB homodimers, and PDGF-AB heterodimers. PDGF-AA, PDGF-AB and PDGF-BB bind to the PDGF receptor-alpha (PDGFR $\alpha$ ), while the PDGFR $\beta$ binds primarily PDGF-BB. After binding and activation of the monomeric $\alpha$ and $\beta$ receptors, these receptors dimerize and activate various intracellular signaling kinase cascades (Fredriksson et al. 2004, Tallquist \& Kazlauskas 2004). PDGF receptors have been shown to be present in the theca and stroma compartments of porcine ovaries (Taylor 2000). PDGF has been demonstrated to affect the proliferation or function of both theca cells (Duleba et al. 1999, Shores \& Hunter 2000, Taylor 2000) and granulosa cells (Hammond et al. 1985, Anderson \& Lee 1993, Lafrance et al. 1993), as well as ovarian surface epithelium (Dabrow et al. 1998). No studies have been reported that examine any effect PDGF may have on the early stages of follicle development.

NRGs are the protein products of a family of related genes. The NRG1 gene is the one for which the most biological functions are known. The NRG1 gene produces several alternatively spliced proteins, some of which are transmembrane proteins with an extracellular domain. This extracellular domain can be cleaved off to release paracrine signaling molecules (Falls 2003). NRGs bind to the Erb $\beta$ receptors, with NRG1 binding to $\operatorname{Erb} \beta 2, \operatorname{Erb} \beta 3$ and Erb $\beta 4$ (Falls 2003). NRG1- $\beta$ is involved in colonization of the genital ridge with primordial germ cells (Kierszenbaum \& Tres 2001), while NRG1- $\alpha$ and NRG1- $\beta$ are both implicated in growth of ovarian cancer cells.

VEGF is a well-characterized growth factor that binds to receptors VEGFR1 and VEGFR2. VEGF is best known as a stimulator of angiogenesis. It is in this role that VEGF has been shown to act in the ovary by stimulating vascular development in the theca layer of pre-antral and antral follicles and stimulating follicle growth (Zimmermann et al. 2003, Hunter et al. 2004, lijima et al. 2005).

The objective of the present study was to investigate what role PDGF, NRG and VEGF may play in the primordial to primary follicle transition. The effect of these growth factors on the primordial follicle transition was examined using a rat ovary organ culture system. The ability of the growth factors to regulate expression of KITL, a known stimulator of primordial follicle development (Parrott \& Skinner 1999), was also examined. A better understanding of the factors that regulate the primordial to primary follicle transition can lead to treatments for some infertilities such as premature ovarian failure.

\section{Materials and Methods}

\section{Organ culture and treatments}

Postnatal 4-day-old rat ovaries were dissected from freshly euthanized rat pups. All animal protocols were approved by the Washington State University Animal Care and Use Committee. Whole ovaries were cultured as previously described (Nilsson et al. 2001) on floating filters $(0.4 \mu \mathrm{m}$ Millicell-CM, Millipore, Bedford, MD, USA) in $0.5 \mathrm{ml}$ Dulbecco's Modified Eagle's MediumHam's F-12 medium (1:1, vol/vol) containing $0.1 \%$ BSA (Sigma), 0.1\% Albumax (Gibco BRL), $27.5 \mu \mathrm{g} / \mathrm{ml}$ transferrin, $200 \mathrm{ng} / \mathrm{ml}$ insulin (human recombinant, Sigma), and $0.05 \mathrm{mg} / \mathrm{ml}$ L-ascorbic acid (Sigma) in a 4-well culture plate (Nunc Plate, Applied Scientific; South San Francisco, CA, USA). A culture experiment consisted of several wells in a culture plate with each well receiving a separate treatment. Two or three ovaries from different rats were placed on floating filters into each well and cultured. Since each ovary receiving a particular treatment is genetically unique and can respond independently to that treatment, then each ovary is considered an experimental unit $(n=1)$. Treatments during organ culture included recombinant rat PDGF-AB heterodimer (R\&D Systems, Inc.; Minneapolis, MN, USA) at $50 \mathrm{ng} / \mathrm{ml}$, rat KITL (Amgen; Thousand Oaks, CA, USA) at $50 \mathrm{ng} / \mathrm{ml}$, anti-PDGF neutralizing antibody (R\&D Systems) at $20 \mu \mathrm{g} / \mathrm{ml}$, 
human NRG1- $\beta 1$ extracellular domain (R\&D Systems) at $50 \mathrm{ng} / \mathrm{ml}$, human NRG1- $\beta 1$ EGF domain (R\&D Systems) at $50 \mathrm{ng} / \mathrm{ml}$, or rat VEGF (R\&D Systems) at $50 \mathrm{ng} / \mathrm{ml}$. Preliminary experiments testing the effects of NRG1- $\beta 1$ EGF domain and VEGF at $250 \mathrm{ng} / \mathrm{ml}$ in culture demonstrated no difference than experiments performed at $50 \mathrm{ng} / \mathrm{ml}$ (data not shown). This suggest that $50 \mathrm{ng} / \mathrm{ml}$ is at or above the maximum effective dose for these growth factors. Medium was supplemented with penicillin and streptomycin to prevent bacterial contamination. After culture, ovaries were fixed, sectioned and stained with hematoxylin and eosin (H\&E) for use in morphological analysis. Alternatively, if mRNA levels were to be measured from cultured ovaries, after culture ovaries from one treatment group were pooled and homogenized in $1 \mathrm{ml}$ Trizol (Gibco BRL) and stored at $-20^{\circ} \mathrm{C}$ until RNA isolation.

\section{Morphological evaluation}

Four-day-old rat ovaries were fixed fresh or cultured for 2 weeks and then fixed in Bouin's solution $(0.9 \%$ picric acid, 9\% formaldehyde, 5\% acetic acid) for 1-2 h. Ovaries were paraffin embedded and sectioned at 3-5 $\mu \mathrm{m}$. Ovaries were de-paraffinized in xylenes and hydrated through an ethanol series. Sections were stained with hematoxylin and eosin using standard protocols. The number of follicles at each developmental stage was counted in two serial sections and averaged from the largest cross-sections through the center of the ovary. The oocyte nucleus had to be visible in a follicle in order for the follicle to be counted. Normally, 100-200 follicles were present in a cross-section. Previously, it has been demonstrated that the total follicle number per section does not change after 2 weeks of culture compared to freshly isolated 4-day-old ovaries (Parrott \& Skinner 1999). Follicles were classified as either primordial (stage 0), or as one of the developing preantral stages (stages 1-4) as described previously (Parrott \& Skinner 1999). Briefly, primordial follicles consist of an oocyte partially or completely encapsulated by squamous pre-granulosa cells. Developing (stages 1-4) follicles contain successively more cuboidal granulosa cells in layers around the oocyte (Parrott \& Skinner 1999, Nilsson et al. 2001). The results of follicle counting are presented as percentages (\%primordial vs \%developing) to account for differences between individual mice in total number of oocytes per section.

\section{Immunohistochemistry}

Localization of PDGF protein was determined by immunohistochemical analysis. Rat ovaries were fixed and prepared for immunostaining as for H\&E staining as described above. Antigens were exposed by boiling sections for $5 \mathrm{~min}$ in $0.01 \mathrm{M}$ sodium citrate buffer at $\mathrm{pH}$
6.0. A solution of $10 \%$ goat serum in PBS was used as a blocking agent prior to incubating sections with primary antibody overnight at $4{ }^{\circ} \mathrm{C}$. Slides were incubated with polyclonal rabbit anti-human PDGF antibody (Santa Cruz Biotechnology, Inc.; Santa Cruz, CA) at $10 \mu \mathrm{g} / \mathrm{ml}$ overnight at $4{ }^{\circ} \mathrm{C}$. Secondary antibody (biotinylated goat antirabbit IgG, Vector, Burlingame, CA, USA) was detected by using the Vectastain kit (Vector) and diaminobenzadine (Vector). Negative controls were incubated in the presence of non-immune rabbit IgG as a primary antibody at $10 \mu \mathrm{g} / \mathrm{ml}$.

\section{Real-time PCR}

Ovaries were isolated from 4-day-old rats and placed into culture as described above. Cultured ovaries were treated for 2 days with recombinant rat PDGF-AB heterodimer (R\&D Systems) at $50 \mathrm{ng} / \mathrm{ml}$, or rat $\mathrm{KITL}$ (Amgen) at $50 \mathrm{ng} / \mathrm{ml}$, or were left untreated as controls. Three ovaries from the same culture well were pooled to make each RNA sample. RNA was extracted using the Trizol reagent (Sigma). RNA samples were DNAse treated using the TURBO-DNA-free kit (Ambion, Austin, TX). Two micrograms total RNA from each sample was reverse transcribed to CDNA using a standard oligo-dT RT protocol in a reaction volume of $25 \mu \mathrm{l}$. cDNA samples were diluted $1: 10$ and $2 \mu$ of diluted sample/ well was used as template for real-time PCR analysis. Each sample was run in triplicate. The Platinum SYBR Green qPCR Supermix kit (Invitrogen) was used according to manufacturers instructions. The KITL primers were rKL-720, 5'ATTTATGTTACCCCCTGTTGCAGCC $3^{\prime}$ and rKL-859, 5'CAATTACAAGCGAAATGAGAGCCG3'. The ribosomal protein gene S2 was used as a references standard for real-time PCR. The S2 reference gene primers were $\mathrm{rS} 2-\mathrm{F}, 5^{\prime} \mathrm{CTGCTCCTGTGCCCAA-}$ GAAG3' and rS2-R, 5'AAGGTGGCCTTGGCAAAGTT3'. Ribosomal S2 mRNA expression does not change in ovarian cells treated with hormones (Kezele et al. 2005a). Real-time PCR was performed on an ABI7000 real-time machine with the following protocol: $60{ }^{\circ} \mathrm{C} 2 \mathrm{~min}, 95^{\circ} \mathrm{C} 10 \mathrm{~min}$, then 40 cycles of $95^{\circ} \mathrm{C} 20 \mathrm{~s}$ and $68{ }^{\circ} \mathrm{C} 90 \mathrm{~s}$. Fluorescent detection data were analyzed such that KITL product levels were normalized to S2 gene levels, and then PDGF- and KITL-treated sample KITL levels were normalized to untreated control KITL levels.

\section{Microarray analysis}

RNA was hybridized to the Affymetrix (Affymetrix; Santa Clara, CA) rat 2302.0 gene chip. The Genomics Core in the Center for Reproductive Biology at Washington State University performed the analysis as previously described (McLean et al. 2002, Shima et al. 2004). Briefly, RNA from control and KITL-treated $(50 \mathrm{ng} / \mathrm{ml}$ 
for 2 days as described above) whole cultured ovaries was reverse transcribed into cDNA and CDNA was transcribed into biotin labeled RNA. Biotin labeled RNA was then hybridized to the Affymetrix 2302.3 gene chips. Each gene set is composed of 16 pairs of 24-mer oligonucleotides, with one sense strand specific for the gene and one anti-sense strand with single point mutations for use as comparative negative control. The oligonucleotides span the gene so $5^{\prime}$ and $3^{\prime}$ regions are contributing to the final signal obtained. Biotinylated RNA was then visualized by labeling with phycoerythrincoupled avidin. The microarray was scanned on a Hewlett-Packard Gene Array Scanner (Hewlett-Packard Co.; Palo Alto, CA, USA). Two microarray chips from two different RNA samples were analyzed for each of the control and KITL-treated ovary preparations.

\section{Bioinformatics}

Microarray output was examined visually for excessive background noise and physical anomalies. GCOS software (Affymetrix) was used for analyses. An absolute analysis using GCOS was performed to assess the relative abundance of the transcripts based on signal and detection (present, absent, or marginal) for the 16 different oligonucleotides per gene and comparison for analysis. The absolute analysis from GCOS was imported into GeneSpring 7.0 software (Silicon Genetics; Redwood City, CA). The data were normalized within GeneSpring using the default/recommended normalization methods. These include setting of signal values below $0.01-0.01$, total chip normalization to the 50th percentile, and normalization of each gene to the median. These normalizations allowed for the visualization of data based on relative abundance at any given time point rather than compared to a specific control value. Means of the raw signal values for control or KITLtreated replicate gene arrays were used to determine expression or change in expression of mRNA for selected genes. Previous studies have shown that microarray data correlate well with real-time quantitative PCR and Northern analysis (McLean et al. 2002, Sadate-Ngatchou et al. 2004).

\section{Statistics}

Pair comparisons were performed using Student's $t$-test. Multiple comparison tests were performed using Dunnet's analysis after a significant difference had been found with ANOVA. Dunnet's test compares each treatment group to the designated control group. In the case of real-time PCR data, in which all values are normalized so that controls are equal to 1 , a one-sample $t$-test was performed to test if the means differ significantly from 1.0. Groups were considered significantly different if $P \leq 0.05$. All statistics were calculated with the help of GraphPad Prism version 3.0a for Macintosh, GraphPad Software (San Diego, CA, USA).

\section{Results}

Ovaries of 4-day-old rats contain predominately primordial follicles. In order to determine the effects of growth factors on the primordial to primary follicle transition, ovaries from 4-day-old rats were placed into culture and treated with PDGF $(50 \mathrm{ng} / \mathrm{ml})$, anti-PDGF neutralizing antibody $(20 \mu \mathrm{g} / \mathrm{ml})$, KITL $(50 \mathrm{ng} / \mathrm{ml}), \quad N R G 1-\beta 1$ $(50 \mathrm{ng} / \mathrm{ml})$, VEGF $(\mathrm{ng} / \mathrm{ml})$ or were left untreated as negative controls. After 2 weeks, the ovaries were fixed, sectioned, and stained for morphological evaluation.

The total number of combined primordial and developing follicles per ovary cross-section was $151 \pm 10$ for controls, $116 \pm 9$ for PDGF-treated ovaries, $130 \pm 13$ for anti-PDGF treated ovaries, and $114 \pm 2$ for KITL-treated ovaries. Approximately, 1500 follicles per treatment were counted for this study. These total ovary counts are not significantly different (using an ANOVA analysis) between treatment groups, indicating that no treatments result in a loss or gain in follicles compared to controls. These results are similar to those found by Parrott \& Skinner (1999). Treatments can result in a change in the relative proportion of primordial and developing follicles. PDGF-treatment resulted in a significant $(P<0.05)$ increase in the percentage of developing follicles compared to the percentage of developing follicles in controls (Fig. 1). This is necessarily accompanied by a concomitant decrease in the percentage of primordial follicles compared to that of controls. Observations indicate an increase in the rate of primordial to primary follicle transition. Conversely, ovaries treated with anti-PDGF neutralizing antibody were found to have a significant $(P<0.05)$ decrease in primary follicles indicating a decrease in primordial to primary follicle transition compared to controls. KITL is known to stimulate primordial to primary follicle transition (Parrott \& Skinner 1999) and was used as a positive control for the organ culture system. KITL-treatment resulted in a significant $(P<0.05)$ increase in the proportion of primary follicles indicating an increase in primordial to primary follicle transition (Fig. 1).

The actions of NRG and VEGF were also evaluated using the ovarian organ culture procedure. Ovaries from 4-day-old rats were placed into culture and treated with NRG1- $\beta 1$ (50 ng/ml), VEGF $(50 \mathrm{ng} / \mathrm{ml})$ or were left untreated as controls. Neither NRG1- $\beta 1$ nor VEGF were shown to promote the primordial to primary follicle transition (Fig. 2).

An immunohistochemical procedure was performed to localize PDGF protein in ovaries. Cultured 4-day-old ovaries have primordial follicles as well as a variety of developing pre-antral follicles. Anti-PDGF antibody (Santa Cruz Biotechnology, Inc.) was used to localize PDGF in both freshly isolated 4-day-old rat ovaries 


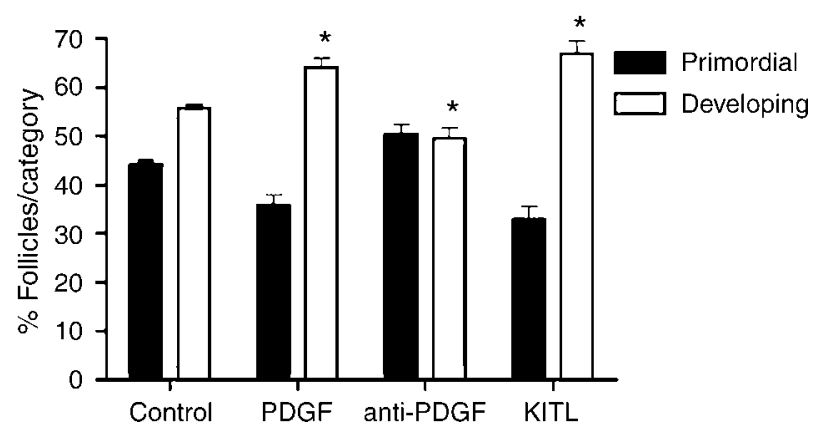

Figure 1 Effect of PDGF-treatment on primordial to primary follicle transition in cultured ovaries. Ovaries from 4-day-old rats were placed into culture for 14 days. Cultured ovaries were treated with PDGF, antiPDGF neutralizing antibody, KITL or were left untreated as controls. After culture all ovaries were fixed, stained and subjected to morphological analysis. The follicles per ovary cross-section were categorized as being either primordial or developing (which includes all follicles having undergone the primordial to primary transition). Data are presented as the mean percentage \pm s.E.M. with data pooled from four separate experiments ( $n=6-12$ ovaries per treatment group). One-way ANOVA showed a significant $(P<0.0001)$ effect of treatment. Asterisks indicate that the percentage of developing follicles for a treatment is significantly $(P<0.05)$ different than that of the control by post-hoc Dunnet's test.

and 4-day-old rat ovaries after culture for 14 days. Immunohistochemical localization indicated that PDGF protein was present in the oocytes of both primordial and developing follicles (Fig. 3). From examination of staining intensity, it is possible that PDGF protein expression is higher in the oocytes of developing rather than primordial follicles. However, one cannot exclude the possibility that differences in fixation or handling of ovaries resulted in these staining differences. There was negligible staining in the surrounding somatic cells (Fig. 3).

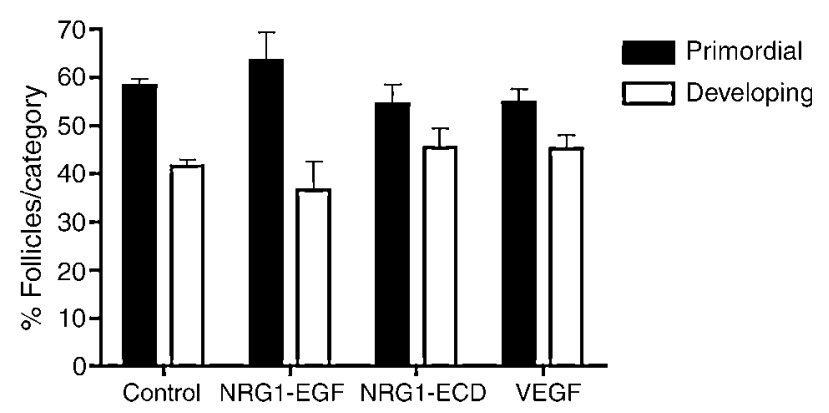

Figure 2 Lack of effect of NRG1 or VEGF-treatment on primordial to primary follicle transition in cultured ovaries. Ovaries from 4-day-old rats were placed into culture for 14 days. Cultured ovaries were treated with NRG1-EGF, NRG1-ECD, VEGF or were left untreated as controls. After culture all ovaries were fixed, stained and subjected to morphological analysis. The follicles per ovary cross-section were categorized as being either primordial or developing, which includes all follicles having undergone the primordial to primary transition. Data are presented as the mean percentage \pm S.E.M. with data pooled from three separate experiments ( $n=3-5$ ovaries per treatment group). Oneway ANOVA showed no significant $(P>0.05)$ effect of treatment.
Four-day-old rat ovaries were cultured for 2, 5, 10 or 14 days in the presence or absence of KITL $(50 \mathrm{ng} / \mathrm{ml})$ in order to determine the appropriate length of culture prior to collecting tissue for morphological analysis vs collecting RNA for gene expression analysis. After 2, 5, 10 and 14 days KITL-treated and control ovaries were fixed, stained and subjected to morphological analysis. Results indicated that no statistically significant morphological difference in follicle transition was apparent between treated and control ovaries at 2 or 5 days, but that at 10 and 14 days of culture KITL-treated ovaries had an increased percentage of developing follicles compared to controls (Fig. 4). These results suggest that mRNA collected from ovaries after 2 days of treatment with growth factors would reflect changes in gene expression due to the treatment, without reflecting changes in gene expression due to a different population of follicles and differentiated cells.

RNA was isolated from ovaries cultured for 2 days with or without PDGF-treatment $(50 \mathrm{ng} / \mathrm{ml})$. Real-time PCR analysis of KITL expression revealed that KITL mRNA was modestly, but significantly $(P<0.05)$, increased by PDGFtreatment (Fig. 5). RNA was also isolated from ovaries cultured for 2 days with or without KITL-treatment (50 ng/ $\mathrm{ml}$ ) and that RNA used for microarray analysis using the Affymetrix 2302.0 rat chip. Selected genes related to PDGF and PDGF receptors were analyzed. No change in mRNA levels were seen between control and KITL-treated ovaries for PDGFa, PDGFb, PDGFc, PDGFd, PDGF receptor alpha (PDGFRa), PDGF receptor beta (PDGFRb), or PDGFa-associated protein 1 (Table 1). Therefore, PDGF was found to stimulate expression of KITL mRNA, but KITL had no effect on PDGF or PDGF receptor expression. KITLtreatment had no effect on expression of NRG1, the NRG receptor signaling pathway protein Tob2, VEGFa isoform or VEGF receptor (Table 1). KITL-treatment did stimulate the expression of mRNA for the NRG receptor signaling pathway protein Tob1 and the VEGFc isoform (Table 1). As previously reported, the microarray data have been validated with an alternate procedure involving quantitative PCR analysis (Kezele et al. 2005b).

\section{Discussion}

Rat ovaries were cultured in the presence of PDGF or neutralizing antibody to PDGF. Morphological evaluation of the treated ovaries indicates that PDGF induces a moderate but significant increase in primordial to primary follicle transition. Conversely, treatment with an antibody that neutralizes endogenous levels of PDGF in the ovary results in a significant decrease in primordial follicle transition. These data suggest that ovarian expression of PDGF can regulate the rate at which primordial follicles leave the resting pool and begin developing. Immunohistochemical analysis indicates that PDGF protein is present in oocytes of primordial 


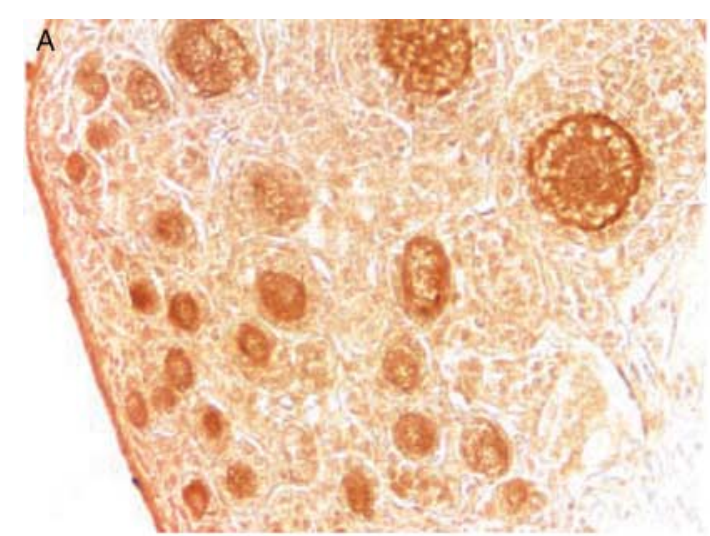

cultured 4-day anti-PDGF

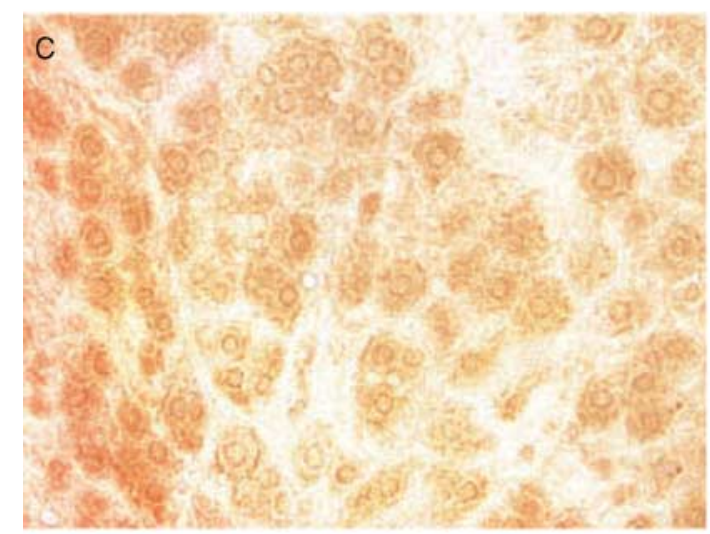

4-day anti-PDGF

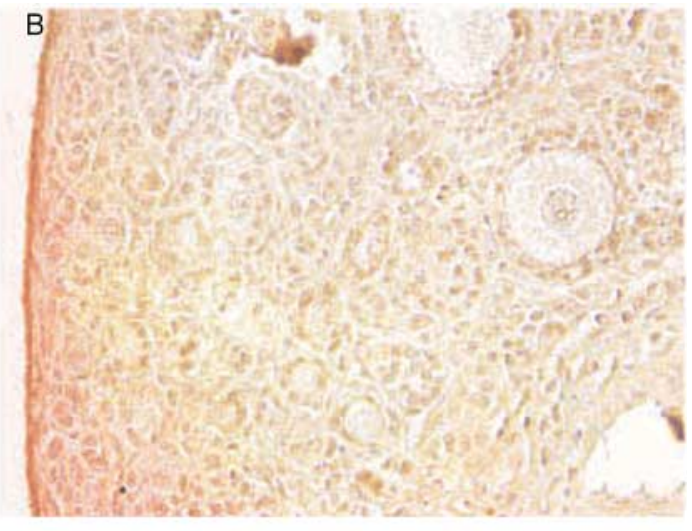

cultured 4-day non-immune IgG

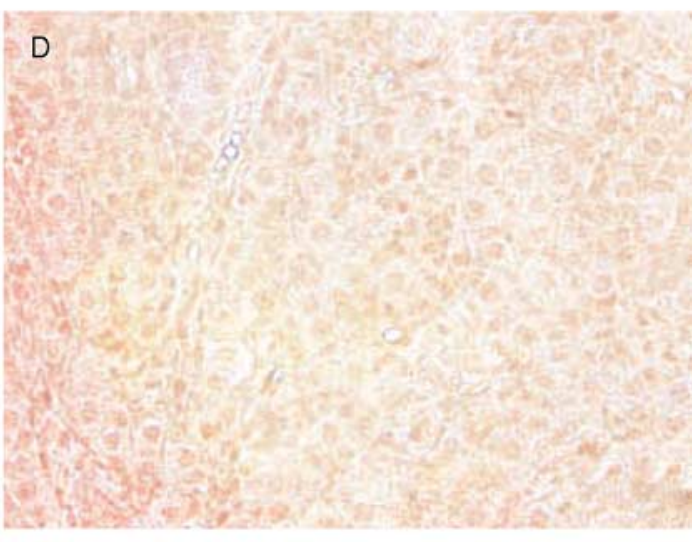

4-day non-immune IgG

Figure 3 Immunohistochemical localization of PDGF protein in cultured ovaries. The presence of PDGF protein is indicated by a dark brown stain in ovary sections. A) Four-day-old ovaries cultured for 14 days showing PDGF staining at high intensity in oocytes. B) Control cultured ovary section stained using non-immune IgG as a primary antibody. C) Freshly isolated 4-day-old ovaries showing PDGF staining in the oocytes of primordial follicles. D) Control freshly isolated ovary section stained using non-immune $\lg G$ as a primary antibody. Images are representative of two different experiments using ovaries from different rats. Microscope magnification $=400 \times$. Total microscope magnification at the time of image capture was $400 \times$.

and early developing follicles. PDGF receptor localization and action have previously been shown in the somatic granulosa and theca cell populations (Hammond et al. 1985, Anderson \& Lee 1993, Lafrance et al. 1993, Duleba et al. 1999, Shores \& Hunter 2000, Taylor 2000). PDGF is similar to bFGF/FGF2 in that both paracrine growth factors are expressed by the oocyte and promote the primordial to primary follicle transition (van Wezel et al. 1995, Nilsson et al. 2001) (Fig. 6). It is not surprising that a process so vital to reproduction is regulated by multiple factors and may feature redundancy.

Treatment of cultured ovaries with PDGF resulted in an increase in KITL expression. This suggests that one mechanism by which PDGF promotes primordial to primary follicle transition is by stimulating KITL mRNA expression, which itself promotes primordial follicle transition (Parrott \& Skinner 1999). Previous investigations have also demonstrated that PDGF can increase expression of KITL in mast cells (Hiragun et al. 1998). In addition, in cultured rat ovaries it has been shown that bFGF treatment, which is known to promote primordial

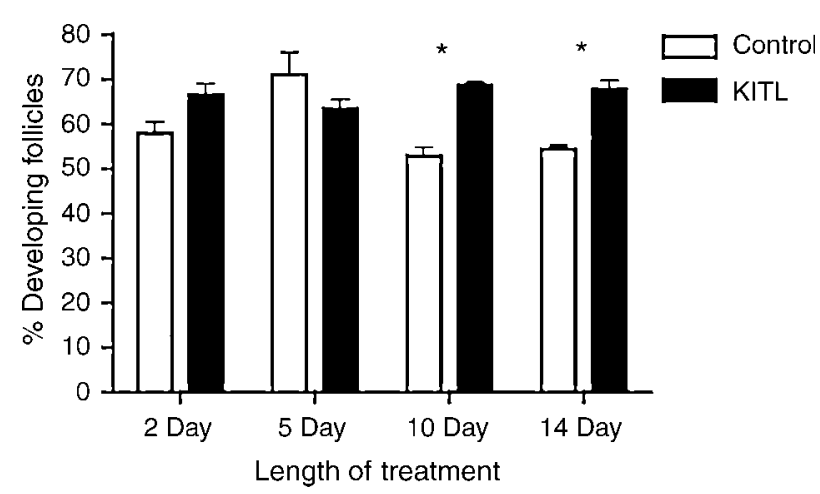

Figure 4 Effect of KITL-treatment over time on primordial to primary follicle transition in cultured ovaries. Ovaries from 4-day-old rats were placed into culture for 2, 5, 10, or 14 days in the absence or presence of KITL. Following culture all ovaries were fixed, stained and subjected to morphological analysis. The follicles per ovary cross-section were categorized as either primordial or developing. Data are presented as the mean percentage \pm S.E.M. with data pooled from three different experiments ( $n=3-6$ ovaries per treatment group). Asterisks indicate that a KITL-treated group is significantly $(P<0.05)$ different from its control at that time point by Student's $t$-test. 


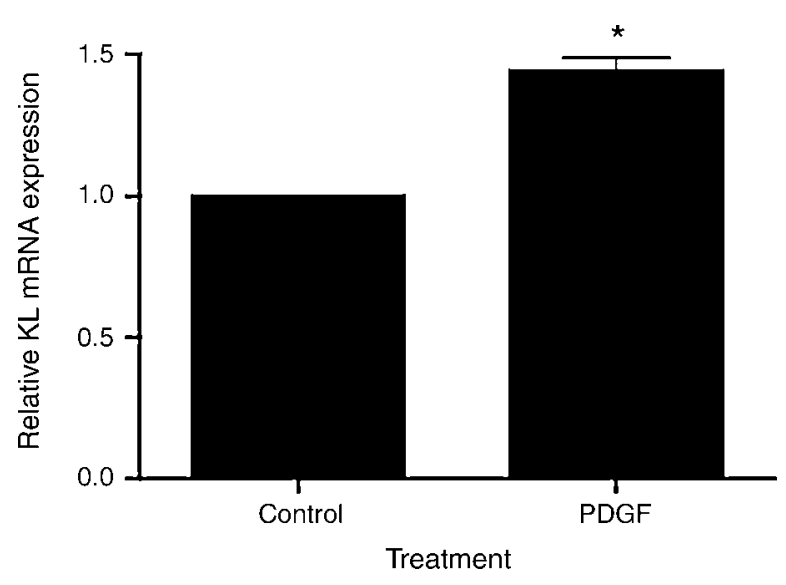

Figure 5 Kit ligand (KITL) mRNA expression in cultured ovaries in response to PDGF-treatment. Ovaries from 4-day-old rats were placed into culture and treated with PDGF or were not treated for 2 days. Realtime PCR was performed on RNA isolated from cultured whole ovaries to determine levels of KITL mRNA expression. Data are expressed as KITL mRNA/S2 mRNA normalized to untreated control values. Data are from three separate experiments with the mean \pm S.E.M. presented. Asterisk indicates a significant difference $(P<0.05)$ from control as determined by a one-sample $t$-test.

follicle transition, will also increase KITL mRNA expression (Nilsson et al. 2001, Nilsson \& Skinner 2004). This suggests that one stimulatory growth factor inducing expression of another stimulatory paracrine growth factor may be a common mechanism for regulating cell growth and differentiation in the local follicle environment (Fig. 6).

Neither NRG1 nor VEGF were shown to promote primordial to primary follicle transition, even though mRNA expression of these genes has been shown to change during follicle transition (Kezele et al. 2005b).
This suggests that these growth factors are either involved in some signaling process other than promoting primordial follicle transition, or that they require as yet unknown cofactors to affect follicle transition. VEGF protein expression has been demonstrated in developing primary, but not primordial follicle oocytes (Celik-Ozenci et al. 2003). Further investigations will be needed to determine the role these growth factors play in early follicle development.

The results from the present experiments indicate that PDGF can join the growing list of extracellular signaling factors that regulate the primordial to primary follicle transition. The actions of some of these factors are summarized in Fig. 6. KITL from granulosa cells acts on the oocyte and also upon the surrounding stroma to recruit theca cells (Parrott \& Skinner 1999, Parrott \& Skinner 2000). Theca/interstitial cells produce BMP4, which acts as a follicle survival factor (Nilsson \& Skinner 2003). KGF, also from the theca, acts on granulosa cells to promote KITL expression and follicle development (Kezele et al. 2005a). Granulosa cells produce LIF that acts on the oocyte as well as on other granulosa cells (Nilsson et al. 2002). Insulin acts in an endocrine manner on the oocyte (Kezele et al. 2002b). $\mathrm{AMH} / \mathrm{MIS}$ from larger growing follicles acts to inhibit the primordial to primary follicle transition (Baarends et al. 1995, Durlinger et al. 1999, Durlinger et al. 2001). The oocyte produces bFGF that acts upon the granulosa and theca cells (Nilsson et al. 2001). Similar to PDGF, bFGF also stimulates KITL expression to facilitate primordial follicle development (Nilsson \& Skinner 2004). In this study, it is proposed that the oocyte produces PDGF, which acts upon surrounding granulosa and theca/interstitial cells to promote primordial follicle transition (Fig. 6). In summary, a network of compensatory cell-cell

Table 1 Microarray gene expression data for selected genes from duplicate RNA samples isolated from 4-day-old rat ovaries cultured for 2 days in the absence (control) or presence of $50 \mathrm{ng} / \mathrm{ml}$ kit ligand ( $\mathrm{KITL}$ ). Data are expressed as the mean \pm s.E.M. of the scaled raw signal values, along with the NCBI Genbank accession number for each gene. Asterisk $(-)$ indicates a significant $(P<0.05)$ mRNA expression difference between KITL-treated and control samples.

\begin{tabular}{|c|c|c|c|c|c|}
\hline \multirow[b]{2}{*}{ Common name } & \multicolumn{2}{|c|}{ Control } & \multicolumn{2}{|c|}{$\mathbf{K L}$} & \multirow[b]{2}{*}{ Genbank no. } \\
\hline & Mean & \pm S.E.M. & Mean & \pm S.E.M. & \\
\hline PDGFa & 99 & 11 & 87 & 10 & L06238 \\
\hline PDGFa & 128 & 10 & 150 & 14 & BE100812 \\
\hline PDGFa & 170 & 19 & 221 & 50 & AA866419 \\
\hline PDGFRa & 1187 & 74 & 1135 & 114 & Al232379 \\
\hline PDGFRb & 105 & 20 & 110 & 12 & Al071374 \\
\hline PDGFRb-like & 67 & 7 & 81 & 22 & BM384311 \\
\hline PDGFa-associated protein & 1078 & 63 & 1076 & 106 & NM_022595 \\
\hline Neuregulin 1 & 282 & 37 & 235 & 25 & U02315 \\
\hline $\begin{array}{l}\text { Transducer of ERBB2 } 1 \\
\text { (Tob1) (NRG receptor) }\end{array}$ & 256 & 20 & $318^{*}$ & 43 & NM_133317 \\
\hline $\begin{array}{l}\text { Transducer of ERBB2 } 2 \\
\text { (Tob2) (NRG receptor) }\end{array}$ & 98 & 8 & 112 & 11 & BI275222 \\
\hline VEGFa & 44 & 14 & 51 & 7 & AF080594 \\
\hline VEGFc & 117 & 10 & $151^{*}$ & 14 & NM_053653 \\
\hline VEGF receptor 2 (KDR) & 463 & 28 & 482 & 46 & U93307 \\
\hline
\end{tabular}




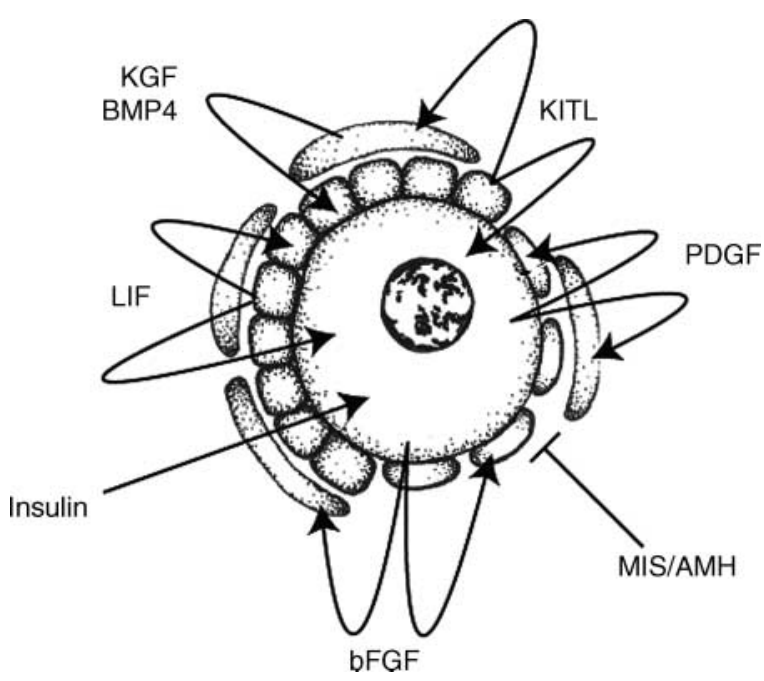

Figure $6 \mathrm{~A}$ model of the regulation of the primordial to primary follicle transition by paracrine growth factors, including the actions of platelet-derived growth factor (PDGF), basic fibroblast growth factor (bFGF), leukemia inhibitory factor (LIF), bone morphogenetic protein-4 (BMP4), keratinocyte growth factor (KGF), Anti-Müllerian Hormone/Müllerian inhibitory substance $(\mathrm{AMH} / \mathrm{MIS})$, and insulin.

interactions involving multiple growth factors is required to modulate the rate of primordial follicle transition and subsequent follicular growth. A more complete understanding of the molecular and cellular control of primordial follicle development will provide insights into potential new therapeutic targets to treat certain types of infertility or to control the transition to menopause in women.

\section{Acknowledgements}

We would like to thank Dr Ingrid Sadler-Riggleman, Mr Jacob Stansfield and Ms Michelle Schmidt for their invaluable technical assistance. Thanks also to Ms Jill Griffin for assistance in preparation of the manuscript. We acknowledge the use of the Center for Reproductive Biology, Genomics and Bioinformatics Core Laboratories, and technical assistance of Derek Pouchnik. This work was supported by NIH grants to Michael K Skinner (HD043093). The authors declare that there is no conflict of interest that would prejudice the impartiality of this scientific work.

\section{References}

Anderson E \& Lee GY 1993 The participation of growth factors in simulating the quiescent, proliferative, and differentiative stages of rat granulosa cells grown in a serum-free medium. Tissue Cell $\mathbf{2 5}$ 49-72.

Baarends WM, Uilenbroek JT, Kramer P, Hoogerbrugge JW, van Leeuwen EC, Themmen AP \& Grootegoed JA 1995 Antimullerian hormone and anti-mullerian hormone type II receptor messenger ribonucleic acid expression in rat ovaries during postnatal development, the estrous cycle, and gonadotropininduced follicle growth. Endocrinology 136 4951-4962.
Celik-Ozenci C, Akkoyunlu G, Kayisli UA, Arici A \& Demir R 2003 Localization of vascular endothelial growth factor in the zona pellucida of developing ovarian follicles in the rat: a possible role in destiny of follicles. Histochemistry and Cell Biology 120 383-390.

Cran DG \& Moor RM 1980 The development of oocytes and ovarian follicles of mammals. Science Progress 66 371-383.

Dabrow MB, Francesco MR, McBrearty FX \& Caradonna S 1998 The effects of platelet-derived growth factor and receptor on normal and neoplastic human ovarian surface epithelium. Gynecologic Oncology $7129-37$.

Dube JL, Wang P, Elvin J, Lyons KM, Celeste AJ \& Matzuk MM 1998 The bone morphogenetic protein 15 gene is $X$-linked and expressed in oocytes. Journal of Molecular Endocrinology 12 1809-1817.

Duleba AJ, Spaczynski RZ, Arici A, Carbone R \& Behrman HR 1999 Proliferation and differentiation of rat theca-interstitial cells: comparison of effects induced by platelet-derived growth factor and insulin-like growth factor-I. Biology of Reproduction $\mathbf{6 0}$ 546-550.

Durlinger AL, Gruijters MJ, Kramer P, Karels B, Ingraham HA, Nachigal MW, Uilenbroek JT, Grootgoed JA \& Themmen AP 2001 Anti-Mullerian hormone attenuates the effects of $\mathrm{FSH}$ on follicle development in the mouse ovary. Endocrinology 142 4891-4899.

Durlinger AL, Gruijters MJ, Kramer P, Karels B, Ingraham HA, Nachtigal MW, Uilenbroek JT, Grootegoed JA \& Themmen AP 2002 Anti-Mullerian hormone inhibits initiation of primordial follicle growth in the mouse ovary. Endocrinology 143 1076-1084.

Durlinger AL, Kramer P, Karels B, de Jong FH, Uilenbroek JT, Grootegoed JA \& Themmen AP 1999 Control of primordial follicle recruitment by anti-Mullerian hormone in the mouse ovary. Endocrinology 140 5789-5796.

Faddy MJ 2000 Follicle dynamics during ovarian ageing. Molecular and Cellular Endocrinology 163 43-48.

Faddy MJ, Gosden RG, Gougeon A, Richardson SJ \& Nelson JF 1992 Accelerated disappearance of ovarian follicles in mid-life: implications for forecasting menopause. Human Reproduction 7 1342-1346.

Falls DL 2003 Neuregulins: functions, forms, and signaling strategies. Experimental Cell Research 284 14-30.

Fredriksson L, Li H \& Eriksson U 2004 The PDGF family: four gene products form five dimeric isoforms. Cytokine \& Growth Factor Reviews 15 197-204.

Gosden RG, Laing SC, Felicio LS, Nelson JF \& Finch CE 1983 Imminent oocyte exhaustion and reduced follicular recruitment mark the transition to acyclicity in aging $\mathrm{C} 57 \mathrm{BL} / 6 \mathrm{~J}$ mice. Biology of Reproduction 28 255-260.

Hammond JM, Baranao JL, Skaleris D, Knight AB, Romanus JA \& Rechler MM 1985 Production of Insulin-like Growth Factors by Ovarian Granulosa Cells. Endocrinology 117 2553-2555.

Hiragun T, Morita E, Tanaka T, Kameyoshi Y \& Yamamoto S 1998 A fibrogenic cytokine, platelet-derived growth factor (PDGF), enhances mast cell growth indirectly via a SCF- and fibroblastdependent pathway. The Journal of Investigative Dermatology 111 213-217.

Hirshfield AN 1991 Development of follicles in the mammalian ovary. International Review of Cytology 124 43-101.

Horie K, Takakura K, Taii S, Narimoto K, Noda Y, Nishikawa S, Nakayama H, Fujita J \& Mori T 1991 The expression of c-kit protein during oogenesis and early embryonic development. Biology of Reproduction 45 547-552.

Hunter MG, Robinson RS, Mann GE \& Webb R 2004 Endocrine and paracrine control of follicular development and ovulation rate in farm species. Animal Reproduction Science 82-83 461-477.

lijima K, Jiang JY, Shimizu T, Sasada H \& Sato E 2005 Acceleration of follicular development by administration of vascular endothelial growth factor in cycling female rats. The Journal of Reproduction and Development 51 161-168. 
Johnson J, Bagley J, Shaznik-Wikiel M, Lee HJ, Adams GB, Niikura Y, Tschundy KS, Tilly JC, Cortes ML, Forkert R et al. 2005 Oocyte generation in adult mammalian ovaries by putative germ cells in bone marrow and peripheral blood. Cell 122 303-315.

Johnson J, Canning J, Kaneko T, Pru JK \& Tilly JL 2004 Germline stem cells and follicular renewal in the postnatal mammalian ovary. Nature 428 145-150.

Kezele P, Nilsson E \& Skinner MK 2002a Cell-cell interactions in primordial follicle assembly and development. Frontiers in Bioscience: A Journal and Virtual Library 7 d1990-d1996.

Kezele PR, Nilsson EE \& Skinner MK $2002 b$ Insulin but not insulin-like growth factor-1 promotes the primordial to primary follicle transition. Molecular and Cellular Endocrinology 192 37-43.

Kezele P, Nilsson EE \& Skinner MK 2005a Keratinocyte growth factor acts as a mesenchymal factor that promotes ovarian primordial to primary follicle transition. Biology of Reproduction 73 967-973.

Kezele PR, Ague JM, Nilsson E \& Skinner MK 2005b Alterations in the ovarian transcriptome during primordial follicle assembly and development. Biology of Reproduction 72 241-255.

Kierszenbaum AL \& Tres LL 2001 Primordial germ cell-somatic cell partnership: a balancing cell signaling act. Molecular Reproduction and Development $60277-280$.

Lafrance M, Croze F \& Tsang BK 1993 Influence of growth factors on the plasminogen activator activity of avian granulosa cells from follicles at different maturational stages of preovulatory development. Journal of Molecular Endocrinology 11 291-304.

Laitinen M, Vuojolainen K, Jaatinen R, Ketola I, Aaltonen J, Lehtonen E, Heikinheimo M \& Ritvos O 1998 A novel growth differentiation factor-9 (GDF-9) related factor is co-expressed with GDF-9 in mouse oocytes during folliculogenesis. Mechanisms of Development $\mathbf{7 8}$ 135-140.

Lee WS, Otsuka F, Moore RK \& Shimasaki S 2001 Effect of bone morphogenetic protein-7 on folliculogenesis and ovulation in the rat. Biology of Reproduction 65 994-999.

McLean DJ, Friel PJ, Pouchnik D \& Griswold MD 2002 Oligonucleotide microarray analysis of gene expression in follicle-stimulating hormone-treated rat Sertoli cells. Molecular Endocrinology 16 2780-2792.

Manova K, Huang EJ, Angeles M, De Leon V, Sanchez S, Pronovost SM, Besmer P \& Bachvarova RF 1993 The expression pattern of the c-kit ligand in gonads of mice supports a role for the c-kit receptor in oocyte growth and in proliferation of spermatogonia. Developmental Biology 157 85-99.

Manova K, Nocka K, Besmer P \& Bachvarova RF 1990 Gonadal expression of c-kit encoded at the $\mathrm{W}$ locus of the mouse. Development 110 1057-1069.

Motro B \& Bernstein A 1993 Dynamic changes in ovarian c-kit and Steel expression during the estrous reproductive cycle. Developmental Dynamics: An Official Publication of the American Association of Anatomists 197 69-79.

Nilsson EE, Kezele P \& Skinner MK 2002 Leukemia inhibitory factor (LIF) promotes the primordial to primary follicle transition in rat ovaries. Molecular and Cellular Endocrinology 188 65-73.

Nilsson E, Parrott JA \& Skinner MK 2001 Basic fibroblast growth factor induces primordial follicle development and initiates folliculogenesis. Molecular and Cellular Endocrinology 175 123-130.

Nilsson EE \& Skinner MK 2003 Bone morphogenetic protein-4 acts as an ovarian follicle survival factor and promotes primordial follicle development. Biology of Reproduction 69 1265-1272.
Nilsson EE \& Skinner MK 2004 Kit ligand and basic fibroblast growth factor interactions in the induction of ovarian primordial to primary follicle transition. Molecular and Cellular Endocrinology 214 19-25.

Paredes A, Romero C, Dissen GA, DeChiara TM, Reichardt L, Cornea A, Ojeda SR \& Xu B 2004 TrkB receptors are required for follicular growth and oocyte survival in the mammalian ovary. Developmental Biology 267 430-449.

Parrott JA \& Skinner MK 1999 Kit-ligand/stem cell factor induces primordial follicle development and initiates folliculogenesis. Endocrinology 140 4262-4271.

Parrott JA \& Skinner MK 2000 Kit ligand actions on ovarian stromal cells: effects on theca cell recruitment and steroid production. Molecular Reproduction and Development 55 55-64.

Peters H, Byskov AG, Himelstein-Braw R \& Faber M 1975 Follicular growth: the basic event in the mouse and human ovary. Journal of Reproduction and Fertility 45 559-566.

Rajah R, Glaser EM \& Hirshfield AN 1992 The changing architecture of the neonatal rat ovary during histogenesis. Developmental Dynamics 194 177-192.

Richardson SJ, Senikas V \& Nelson JF 1987 Follicular depletion during the menopausal transition: evidence for accelerated loss and ultimate exhaustion. The Journal of Clinical Endocrinology and Metabolism 65 1231-1237.

Sadate-Ngatchou PI, Pouchnik DJ \& Griswold MD 2004 Identification of testosterone-regulated genes in testes of hypogonadal mice using oligonucleotide microarray. Molecular Endocrinology 18 422-433.

Shima JE, McLean DJ, McCarrey JR \& Griswold MD 2004 The murine testicular transcriptome: characterizing gene expression in the testis during the progression of spermatogenesis. Biology of Reproduction $71319-330$.

Shores EM \& Hunter MG 2000 The influence of blood cells and PDGF on porcine theca cell function in vitro. Animal Reproduction Science 64 247-258.

Tallquist M \& Kazlauskas A 2004 PDGF, signaling in cells and mice. Cytokine \& Growth Factor Reviews 15 205-213.

Taylor CC 2000 Platelet-derived growth factor activates porcine thecal cell phosphatidylinositol-3-kinase-Akt/PKB and ras-extracellular signal-regulated kinase-1/2 kinase signaling pathways via the platelet-derived growth factor-beta receptor. Endocrinology 141 1545-1553.

van Wezel IL, Umapathysivam K, Tilley WD \& Rodgers RJ 1995 Immunohistochemical localization of basic fibroblast growth factor in bovine ovarian follicles. Molecular and Cellular Endocrinology 115 133-140.

Yamamoto S, Konishi I, Nanbu K, Komatsu T, Mandai M, Kuroda H, Matsushita K \& Mori T 1997 Immunohistochemical localization of basic fibroblast growth factor (bFGF) during folliculogenesis in the human ovary. Gynecological Endocrinology 11 223-230.

Zimmermann RC, Hartman T, Kavic S, Pauli SA, Bohlen P, Sauer MV \& Kitajewski J 2003 Vascular endothelial growth factor receptor 2-mediated angiogenesis is essential for gonadotropin-dependent follicle development. The Journal of Clinical Investigation 112 659-669.

Received 23 September 2005

First decision 13 December 2006

Revised manuscript received 7 March 2006

Accepted 28 March 2006 